\title{
Gazing the Diversity Stance in North America: Bringing Practitioner Inquiry into the LIS Classroom
}

\author{
Vanessa Irvin \\ Library and Information Science Program, University of Hawaii-Manoa. Email: irvinv@hawaii.edu
}

This article is an exploration of ways in which LIS educators can consider culture, heritage, and identity as a framework for becoming participatory agents of their teaching practices in the LIS classroom. To support this framework, this discussion introduces the research methodology, practitioner inquiry, as a meaningful approach to studying pedagogical practice and identity in the LIS classroom as a means to LIS educators becoming more self-reflective and aware of the impacts of their own identity construction in their teaching. In this article I am affirming the case for a diversity stance within the North American LIS curriculum. I am also posing additional questions and challenges about LIS identity construction and professional practice as we teach and learn in the classroom.

Keywords: LIS educators, pedagogy, diversity, culture, heritage, identity

\section{Introduction}

D uring the American Library Association (ALA) presidency of Leslie Berger (2006-2007), I submitted a paper to the ALISE annual conference that was entitled, Creating a Seat at the Table: (Still) Seeking Culturally Competent Pedagogy in LIS Education. This was in response to Berger's presidential theme: "libraries build communities". Creating a Seat at the Table was an unpublished discussion piece for round table discourse at the ALISE 2007 conference. My impetus for submitting that paper was the need I saw for we library and information science (LIS) educators to think and talk about ways in which we can employ culturally competent pedagogy for the purpose of building effective learning communities in the LIS classroom. Since then, the conversation centering on LIS cultural competency has continued (e.g. Mestre, 2010; Jaeger, P., Bertot, J., \& Subramaniam, M., 2013; Shorter-Gooden, 2013; Jaeger, P., et al., 2015). There have been some singular strides towards innovative initiatives in the LIS curricula (e.g. the diversity and inclusion track within the iSchool at Maryland's library science program and the cultural heritage informatics concentration at Simmons College). But we await a full scale shift in our educational paradigm to be led by ALA-accreditation LIS standards (COA, 2015).

There are, however, some LIS initiatives which are seeking to address the inequity of cultural representation and engagement within the practitioner ranks of librarianship. For example, the ALA Spectrum Scholar program continues to recruit and sponsor librarians of color and the ALA Office of Literacy and Outreach Services (OLOS) had been merged with the ALA Office of Diversity to now function as a broadened unit to focus and address cultural issues within LIS as the Office for Diversity, Literacy and Outreach Services. Notwithstanding these initiatives, I am still holding that it is LIS educators who are responsible for addressing the homogeneous culture of LIS because of the ways in which we pedagogically approach culture, heritage, and identity of not just library services to diverse populations. We also need to challenge librarians (includ- 
ing ourselves) to reflect upon their own culture, heritage, and identity as a vital aspect of librarian epistemology. I am invested in the ways in which we LIS practitioners define ourselves (or not), and how we reflect upon the impacts of the work we do, based on our identity construction as critical inquiry. For LIS educators this involves examining how we regard and facilitate multi-layered identities within ourselves and within our teaching in the LIS classroom. I am still making a call for LIS education to, not only help to "create a seat at the table" of a healthy, diverse librarianship, but also for LIS faculty to deeply consider who we are as teachers of LIS (culturally). We need to identify what we "do" to be "better" educators with an agency of critical inquiry for pedagogical praxis.

In this article I am therefore "writing back" to Creating a Seat at the Table. I am restating the case for diversity as a tenet of the LIS curriculum, but with added questions and challenges to our thinking about LIS identity construction and professional practice along with our own identity construction as we teach in the LIS classroom. Almost a decade into this discussion, I am using this presentation as an opportunity to beg the question "what are we doing" when we teach LIS?. "Who are we" as we teach our students how to be librarians in a 21st century world? A world that demands inclusion for voicedness that is not just present, but critically present, insisting on not just being seated at the table of a holistic cultural paradigm for LIS, but actively engaged and participating in reflective collaborative research as practitioners of teaching and advising emerging library and information professionals. Thus this work will restate and re-problematize what was said then as the issues are still present. It behooves us to look, and look again, at the questions we ask ourselves and the challenges that we still face. This needs to occur until the snail's pace at which we address our issues, passes us over the finish line of equity, mutual understanding and normalization of diversity as unity.

\section{Unpacking Who We Are, Where We Are: Our Multi-Cultural Selves}

When thinking about the diversity of our librarian workforce, we can find it all too easy to identify ourselves in monolithic terms. For example, we can easily cite data which informs us that eight out of 10 librarians are white women, with 36\% white librarians over the age of 55 , and the rest of the workforce are men $(17 \%)$ and librarians of color $(\sim 12 \%)$ (ALA-APA, 2011; Office of Diversity, 2012; Bourg, 2014; Davis, 2014). Additionally, with librarians of color, we can unpack the multiple cultural groups that are self-organized as ethnic caucuses that promote culturallyappropriate and -specific library services and professional development initiatives. As library and information science (LIS) professionals we often self-identify with a veneer that is "easy": white women, white men, and people of color. With these kinds of surface-oriented categories, we selfidentify as a pretty homogenous group. But in reality what simmers beneath this veneer is actually quite kaleidoscopic.

When we take into consideration the diverse histories and heritages that humans possess, we can see where we must rediscover the diverse identities of the entire population of librarians. In order for a true, authentic diversity movement to occur in LIS, it is vital that we count the multiple cultural identities, constructs, and expressions encapsulated as one representation in all librarians, male, female, other-gendered, and from multiple cultural and social experiences. In this view, all of us are multi-cultural. Thus to be "white" is much more complex than identifying as "American". In turn, the question becomes: Who are we, the librarians? What are our multicultural identities, traditions, and practices when we don't count color or race, but instead count culture, heritage, and identity?

To arrive at an understanding of our profession's true diversity, we do need to start at square one and to acknowledge and unpack LIS as an overwhelmingly white pro- 
fession (Lance, 2005; White 2012; Bourg, 2014). Adkins and Espinal (2004) look at the identity disparities within LIS with a realistic lens of who patrons typically see when they walk into the library. They posit that minority patrons may not feel at ease to approach a librarian of mainstream culture because of a few factors: (1) patrons may perceive librarians as representatives of a monolithic mainstream culture that is a hegemonic space of power and oppressive authority for many minority groups, (2) thus patrons may not be attracted to receiving services from the library, which can decrease usage, and (3) librarians may see themselves as representatives of a monolithic mainstream American culture and unwittingly enact acts of power and authority that are culturally insensitive and inappropriate (Adkins \& Espinal, 2004). Given our profession's demographics it is vital to consider: Within the nuances of mainstream American culture, what is the multi-culturalism of American whites? In turn, what is the multi-culturalism of the majority of American librarians (who are overwhelmingly white)? Again, there is a lot of nuance to whiteness that we must acknowledge, unpack, and add to the conversation of culture, heritage, and identity.

We must take into account all of who we are as LIS professionals and what "cultures" are enacted within those various self-identified constructs. For example, what does it mean to be a queer, disabled, academic librarian in a rural community? For you: what does it mean to be you in the community you currently work and/ or live? What are your multiple heritages? ancestral origins? diverse reading interests? familial cultural traditions? gender constructs? And how do those identities raise questions for you to explore how you approach, practice, and teach librarianship?

With "few candidates of color . . . attracted to the field" this "overwhelmingly white" (Adkins \& Espinal, 2004, p. 52) profession of librarianship currently services an American society of diverse groups such as: $17 \%$ Hispanic, $13 \%$ African American, 5\% LGBTQ over the age of $18,6.6 \%$ Asian, $1.2 \%$ Native American, $18 \%$ physically disabled, $25 \%$ children up to age 18 (of which 5\% aged 13 and up are gay), $12.5 \%$ elderly, and an elusive percentage of homeless persons due to the insidiously transient nature of homelessness (the figure teeters around the 3\%-4\% range from various sources), of which $33 \%$ are youth under the age of 24 years (Henry, M., Cortes, A., and Morris, S., 2013; U.S. Census, 2014). Concerning the homeless school population, the U.S. Department of Education reports that there are 1.36 million homeless children in U.S. public schools as of 2014, which is an eight percent increase from 2012-2013 (Crary \& Leff, 2014; Layton \& Brown, 2015). Suffice it to say that American library patrons, are a pluralistic group of citizens (or not) in need of a variety of informational and cultural resources that reflects their environment, their traditions, and their experiences in America, and beyond. At present, those services are being provided predominantly by American librarians who are typically white and female, with the economic fortitude to be able to achieve a graduate level college education.

Two salient issues stare us in the face here. One is the reality that the American librarian profession is comprised of an overwhelming roster of librarians (89\%) who more than likely subscribe to a demographic of the mainstream American (e.g. white, middle class, $100 \%$ physically functional, English speaking, home-full, etc.). The second issue is that American library patrons are invariably members of diverse cultural groups that do not necessarily subscribe to the demographic of the mainstream American but subscribe to the American idea of "other" (Apple, 2006, pp. 61-62). One might posit: "Well whites go to libraries; they are library patrons, too." Fair enough. However, the issue that raises its snarly head here is access; more specifically, equity of access. Whites dominate mainstream culture in American society as 
a homogenous group based on skin color and race, not culture, heritage and identity. In turn, it is a "packed" American mainstream society that holds historical and contemporary access to informational and cultural resources whether those resources are available in libraries or not. When we think of the prevailing issue of the "digital divide" we recognize this issue of equity of access to be real and true. Libraries and schools in areas where middle and upper class Americans live invariably contain more resources (because higher income communities can provide higher tax dollars for community resources like libraries) and more accessible technologies for a wider range of patrons. Middle and upper class communities also have wider access to various resources because residents can afford cars, cable TV, and home computer devices that provide convenient access to real-time information and cultural activities. Since most librarians are of the mainstream demographic, we can posit that many student librarians enroll into library school from a privileged place of access and the economic wherewithal to have convenient access to information, cultural and artistic activities, as well as a mirrored reality (whites serving whites) while enjoying such social privilege.

As de facto members of an ever-growing, diverse American reading public, we librarians must recognize and acknowledge the diversity and holism of our own personal and professional identities and reading habits and tastes; and I posit that we must do this even moreso if we are LIS educators. Bottom line, our LIS curriculum reflects mainstream American values and identity, and we LIS educators perpetrate the marginalization of American subcultures when we teach LIS without a critical lens of inclusion for a variety of American experience and identity. The ways in which we read our lives and histories during our acts of reading text, creates an identity that we bring to our work (Iser, 1987). For LIS educators, when LIS students approach us, our "ways of read- ing the world" (Freire \& Macedo, 1987) inform and impact our professional practices within teaching, research, and community engagement. We cannot teach who we are unaware we are not; we can only teach who we are aware of.

\section{Studying the Gaze: Practitioner Inquiry}

As information professionals, as much as we research and learn about the reading interests of the reading public to help develop their literacy practices, we must do the same for ourselves, as a means of lifelong learning and professional development. My research with introducing practitioner inquiry to public librarians bares to show that when librarians explore their own reading habits to challenge how they 'are just American' or to reflect on why they've 'never had to consider the question of one's own diversity before', embedded (albeit unintended) assumptions, biases, and societal privileges exacted in professional practice can be recognized, discussed and modified. A most fitting space to begin this important work is in the LIS classroom. The LIS classroom is a space where this introspective level of inquiry can be collaborative, inclusive, critical, and discerning, with the potential to embed a necessary commitment to practitioner inquiry as an ongoing approach to a self-sustaining professional development throughout a librarian's career. For LIS educators, this approach of re-viewing the LIS classroom as a field for meaningful data, can reveal important new understandings about how we participate in class not just as teachers in the classroom, but also as learners.

My research demonstrates that when practicing librarians collaboratively study their professional practices on a consistent basis, that burnout and apathy can decrease because we feel more invested in the meaning and impact of our work. Isolation can decrease because we are more engaged with how we approach patrons, 
colleagues, and our professional selves. Practitioner Inquiry promotes professional self-awareness, self-empathy, and self-care. Professional development from an inquiry stance can increase because we are more committed to our lifelong learning (Cochran-Smith \& Lytle, 2009). Practitioner Inquiry helps us to strategically examine who we are, who we are not, and how we can actively sustain an ongoing curiosity for a holistic professional identity. Practitioner Inquiry is a reflective methodology grounded in critical theory that incorporates various forms of literacy practices for the purpose of collaborative professional development, continuing education, and lifelong learning. Thus practitioner inquiry seeks to ignite professionals to question their own professional practices for the purpose of more deeply understanding why we do what we do, how what we do impacts others in the world, and how we can be "better" at what we do (Lytle, 2008).

Such inquiry-based questions serve as fodder for multimodal growth and development in the inquiry-based LIS classroom. In a profession where questions are currency, questions become tools for instilling critical thinking in pre-service librarians. Questions are no longer challenges that must be overcome in the reference interview or readers' advisory interaction, but rather, questions become portals through which uncertainty is confronted, explored, and made user-friendly for the educational process.

\section{Practitioner Inquiry in the LIS Classroom}

With practitioner inquiry for LIS educators, the professional becomes personal, the practical becomes profound, and the familiar becomes strange. Pedagogical practices are reflected upon on a personal level, but then that personal reflection is exposed and explored within a group of like-minded inquirers for collective feedback (such practice would make for amaz- ing faculty meetings, I would think). Practical methods such as memo writing, data collection, and leisure reading, become profound, strategic approaches to critically question and analyze assumptions, observations, and literary responses that may disrupt and complicate instructional intentions and objectives. Familiar practices such as class research and preparation, teaching, facilitating, and student advising, can become newly strange revelations when put under examination with grouporiented critical discourse. Thus practitioner inquiry can be a strategically sustainable approach to LIS educators engaging their students as a professional learning community of collaborative engagement to "better" the ongoing development of librarianship overall.

As an example of practitioner inquiry in the LIS classroom, reading, in various ways, can take center stage in the theoretical and practicum balance of class discourse amongst students and between students and instructors. As LIS educators, I believe it is requisite that we examine our own approach and practices to reading because rarely, if ever, do our own reading acts and practices come into play as a necessary consideration for our pedagogical identity construction and constitution. Not only is the LIS classroom the perfect place for us to read with students in order to explore ways in which reading practices create powerful librarianship, but also, LIS educators can learn more deeply what it means to teach LIS as readers of research, assignments, and popular literature. Reading becomes questioned, challenged, and confronted as an impetus for studying our gaze of seeking, teaching, and learning together.

In the LIS classroom, knowledge can often be considered a privileged space for the teacher to distill to the learner, particularly since library and information science is a profession based upon meanings and application of knowledge, data, and information. Practitioner Inquiry disrupts normative ideas of who is the teacher and 
who is the student, and problematizes instructor knowledge as the non-negotiable framework for the learning community. In turn, practitioner inquiry forces us to confront our identities as educators and practitioners because LIS educators are truly "librarians to the librarians". We are nudged to look in a mirror that is not only reflective but collective, to ask the question: "Who Are We, the Librarians"?

\section{The Multi-layered, Hybrid-notic Stance}

To further consider the homogeneity of LIS, along with the need for a self-directed critical inquiry stance towards our pedagogical practices in order for our ongoing professional development to be consistent and sustainable, yields that we acknowledge and embrace a multi-layered, hybrid agency to LIS education. This agency is a critical way of being and knowing because we need to constantly ask ourselves hard questions in order to confront truths that point to gaps in the professional selfesteem within LIS as a whole. We LIS educators must accept the fact that the buck for the health of LIS practitioners begins with us, in the LIS classroom.

This agency is a vital responsibility we must recognize and embrace because I posit from my own experience as a librarian educator that many student librarians enter library school with a preconceived notion of what it means to be a librarian and what it takes to become a librarian. This notion is often embedded with the usual stereotypes of the librarian as spinster, isolated, and a voracious reader of books, while the technological world passes us by. I call this student assumption the "patron point of view". Student librarians with no experience with working in libraries come into library school with a patron's point of view thinking that it is going to be easy to "read" books for a year or so, and then qualify to sit behind a desk and answer questions to just a few, select people, with a smile day in and day out.
I have found that such student librarians are often disillusioned to the rigors of not just the mindset of librarianship, let alone the actual practice of the profession. Many LIS students enter library school surprised and overwhelmed by professional competencies we teach such as the competencies outlined at ALISE in 2006 (Berger. 2007).

- creativity

- collaboration

- communication skills

- being change agents

- flexibility (able to adapt to change)

- decision making

- problem solving (to be able to analyze and take action quickly)

- leadership skills

- risk takers

- tech savvy

- political skills of negotiation

Back then, Berger cited LIS faculty as the underscore to librarians actualizing these qualities. She asserted "that the biggest thing library education can do is to instill the passion, commitment and social standing of the values of librarianship" (Berger, 2006). This charge still holds true, especially as we are now a social media world where user populations have also made it clear that they need these kinds of qualities from librarians so that diverse identities and diverse information needs of diverse populations are acknowledged, respected, and addressed. Additionally today, library patrons are demanding that librarians acknowledge, respect, and address the fact that they too, are patrons of the libraries in which they serve. Indeed, we must repeat the lesson to LIS students that we librarians are community members within our libraries, just as we LIS educators are students in our classrooms.

Thus we have to look at who is teaching library school, who is attending library school, and who is seeking library service, all from a cultural/heritage/identity perspective that proactively acknowledges the fact that libraries exist and operate in communities that house a variety of peo- 
ples who are all multi-cultural in nature, and are seeking information and service that honor and reflect who they are. We, as LIS educators serving in a global 21st century society, can no longer afford to not look at our pedagogical practices from a critical lens to consider Berger's competencies, such as: Are we being creative in our teaching practices? Are we collaborative with students and colleagues? Are we change agents to be willing to discuss risky, challenging topics in class? Are we tech savvy to present course content in innovative ways that introduces contemporary technologies? Are we LIS educators still learning? Or are we just teaching?

Additionally, ongoing considerations about demographics, immigration issues, public services for homeless citizens, rural and inner-city services or lack thereof, to technology access for persons with various learning and physical disabilities, and equal education for children of all languages and socio-economic levels, all speak to the imperative need of LIS to be an information- and service-oriented profession that views our philosophies, theories, and praxis from a multi-cultural framework that includes a focus on culture/heritage/ identity as part of wholistic LIS teaching, learning, and praxis. If libraries intend to remain relevant, important and central as informational and cultural resources in a global society, this multi-cultural framework must be addressed, embraced, and standardized in library school. Indeed, we need to ask some important questions. For example, are library schools teaching reference from the lens of servicing the global village? Are library science students being exposed to literature and discourse of a multi-cultural nature? Are LIS educators and students engaged in mutual learning communities where critical inquiry is opening up space to make the comfortable uncomfortable?

Library schools must be up to the challenge of igniting student librarians to the reality that our professional work, regardless of its venue, has socio-cultural purpose and meaning that requires competencies of a social and cultural nature. Because LIS is predominantly white and female, it behooves library schools to ensure that students are taught competencies that create librarians who are culturally aware of their own social and cultural privilege as well as aware of the social and cultural realities of fellow citizens.

\section{The Crux of LIS Educator Learning}

During IFLA's (International Federation of Libraries Associations and Institutions)1998 General Conference in Amsterdam, a paper was presented by the Iivonen research team (who are librarian educators from the University of Finland), that spoke to the need for librarian educators to become culturally self-aware and therefore empowered to embrace and service multicultural patron communities. In their paper, "Analyzing and Understanding Cultural Difference: Experiences from Education in Library and Information Studies" (1998), Iivonen, etal, report on a study of two library science classes, one in Finland, and one in North Carolina, USA, where they compare and contrast library best practices to come to a realization of the following competencies for serving cultural groups in libraries:

It is important to pay attention to how members of various cultures see

i) the nature of people,

ii) a person's relationship to the external environment,

iii) the person's relationship to other people,

iv) the primary mode of the activity,

v) people's orientation to space, and

vi) the person's temporary orientation.

... In addition, [attention is paid to] language and communication styles as a dimension of cultural differences (Iivonen, et al., 1998). 
The Finland team posit that librarians must come out of their shell of seeing themselves from a parochial point of view where such a perspective "neither recognizes other people's different ways of living and working nor appreciates that such differences have serious consequences" (Adler, 1997, as quoted in Iivonen, etal, 1998). The livonen group echoes the sentiments outlined herein that while technology has made our world a smaller place, it still takes the collaboration and interaction of people face to face, heart to heart, to garner true meaning of self, others, and of life. Truly this is the essence of having a practitioner inquiry-based and participatory-oriented learning stance that creates inclusive, collaborative space for exploring the culture/heritage/identity paradigm. Thus, librarian educators must be willing to recognize their own racial, ethnic, heritage, and cultural identity development (Carter and Goodwin, 1994), preferably within a collaborative environment, because an educator's internalization of their own diverse identity is the crux to the interchange of learning for the purpose of teaching. While it may not be practical for LIS educators to go back to school to learn cultural competency for librarianship, initiation of such pedagogy in library school can be a powerful tool through which both teacher and student learn from one another.

It all has to do with contemporariness, relevancy, and respect for librarianship's tradition as a humanistic profession. We have done a lot of work to focus on information technology and librarianship's place within technology (Gorman, 2003). We have played with the buzzwords, "informatics", "social media", and "design" enough to now have new courses, specializations and tracks for these areas, throughout ALA-accredited programs and schools. I believe as a profession we've looked at computers and have figured out how to validate our work with them. But what about the people? When will we do the courageous, messy work to look how we educate professionals who serve in libraries, cultural institutions, and information centers? When will our lens focus on how we evolve our approaches to people? Our ways of understanding one another and ourselves? When will we validate our humanity and insist that such validation is current, relevant, hip, cool, interesting, and necessary for the ongoing progression of our profession? When do we become people-oriented again, creating a throne at the table of LIS to ensure that culture, heritage, and identity, are always at the forefront of everything we think about, talk about, and compute about? When.

\section{Getting On Par}

I do not offer the framework of participatory teaching and learning culture/heritage/identity in librarianship to say let's do it my way. After all, I am a newbie librarian educator, and librarianship is a collaborative profession. However, I am looking for a cogent framework for identity and inquiry work in librarianship to be added to the plate of 'our issues in library education.' Without practitioner inquiry into how we perceive and collaboratively explore culture/heritage/identity, we are missing an important tenet in our discussions of LIS education; a tenet that I passionately feel we may perhaps overlook a bit too easily because the work and commitment to do this work may be considered a bit too hard.

What I am positing is that as a profession still overly focused on technology's impact on praxis; we need to shift to focusing on the people, which includes us as librarians, as teachers of librarians, as culturally competent educators. We do this by initially unmasking our own sense of who we are, allowing ourselves to redefine ourselves from a cultural space that acknowledges personal diverse heritage as the construct for identity formation. This is an unmasking that can be a powerful strategy for we LIS educators gaining a balanced, unbiased, professional lens from which to fortify student librarians to enter the world 
of work as cultural competent librarians. That is truly the end-goal here, an objective we can never forget.

Such practical yet profound educational experiences need to be implanted into all Master of Library Science (MLS) degree programs in North America as a required core course as opposed to an elective. When we direct our attention to the truism that one cannot help another if one does not possess self-knowledge; we recognize that as a helping profession, librarians cannot provide evolved services that are culturally literate until they are culturally empowered and literate themselves. This includes LIS educators.

This position leads us back to the issue of equitable access. I am reminded of Carole Edelsky's idea of cultural activities as "communities of practice" (2006, p. 152). Edelsky informs us that participation is key in cultural activities as communities of practice. She feels that "situated learning focuses on people" (italics mine) participating in cultural activities with the intent of becoming members, of joining the club (p. 152). Edelsky admonishes us that in order for people to have membership in a community of practice, "they must have access to the activity; they have to be privy to its enactment by those who are already central members of the community of practice (p. 152).

While Edelsky is speaking primarily in the context of classroom discourse for second language learners, her advice informs librarianship quite well. For librarians are central members of their community of practice (the library). Thus, as such, if the librarian is not attuned to the culture of the service community, that service community will not feel an entry into the library in which the librarian services and invariably, manages. This is why it is vital that as a profession we centrally position multicultural praxis into library education, so that student librarians are taught cultural competencies that will serve them and their communities well throughout their careers. Steps to such competency would include a reflective lens focusing on self-assessment, immersion of self into multicultural literature and other media, and discourse on worldviews of various American and even international cultural groups, resources, and services.

For the ALA accreditation committee to require a multicultural course as part of the core curriculum for all accredited library schools would be a serious step towards placing librarianship on par with other helping professions such as social work, medicine, and law. Indeed, social workers have to be culturally competent to work with the same communities libraries serve, and doctors and lawyers are conversing about the importance of cultural competency within their respective professions (Weaver, 2004; Voyvodic, 2006).

Indeed, our conversation has been ongoing in recent years with LIS scholars publishing thought-provoking and informative articles on the topics of LIS cultural competency (Jaeger, P. T., Bertot, J. C., \& Franklin, R. E., 2010; Mestre, 2010; Kumasi \& Hill, 2013; Shorter-Gooden, 2013; Jaeger, et al., 2015), and inquiry in the LIS classroom (Overall, 2010). My call in this contribution to that conversation is that we need to combine the two conceptual methods in our teaching of LIS because we, too, are part of the paradigm for competent LIS professional practice.

\section{References}

ALA Allied Professionals Association. (2011). Library workers: Facts and figures. Fact Sheet 2011. http://ala-apa.org/files/2012/03/LibraryWorkers-2011.pdf.

Adkins, D., \& Espinal, I. (2004). The diversity mandate. Library Journal, 129(7), 52-54.

Apple, M. (2006). Educating the "right" way: Market, standards, God, and inequality. (2nd ed.). NY: Routledge/Taylor and Francis.

Berger, L. (2006). Discussion forum remarks. ALISE/ALA/COE Forum on Library Education. Association of Library and Information Science Education with American Library Association. American Library Association Mid-Winter Conference. San Antonio, Texas. January 20-25, 2006. 
Bourg, C. (2014, March 3). The unbearable whiteness of librarianship. Feral Librarian. Blog. https://chrisbourg.wordpress.com/2014/03/03/ the-unbearable-whiteness-of-librarianship/

Carter, R. T. \& Goodwin, A. L. (1994). Racial identity and education. In L. Darling-Hammond (ed.). Review of Research in Education, 20 (pp. 291-336). NY: Teachers College Press.

Cochran-Smith, M. \& Lytle, S.L. (2009). Inquiry as Stance: Practitioner Research in the Next Generation. Practitioners Inquiry. NY: Teachers College.

Committee on Accreditation of the American Library Association (COA). (2015). Standards for Accreditation of Master's Programs in Library and Information Studies. http://bit.ly/1IlDucd

Crary, D., \& Leff, L. (2014, November 18). Number of homeless children in America surges to all-time high: Report. The Huffington Post. http:// www.huffingtonpost.com/2014/11/17/childhomelessless-us_n_6169994.html

Davis, D. (2009). Planning for 2015: The recent history and future supply of librarians. Report. Office for Research and Statistics. Chicago: American Library Association.

Edelsky, C. (2006). With Literacy and Justice for All: Rethinking the Social in Language and Education. Mahwah, NJ: Lawrence Erlbaum.

Freire, P. \& Macedo, D. (1987). Literacy: Reading the Word and the World. South Hadley, MA: Bergin \& Garvey.

Gorman, M. (2003). The Enduring Library: Technology, Tradition, and the Quest for Balance. Chicago: American Library Association.

Henry, M., Cortes, A., and Morris, S. (2013). The 2013 Annual Homeless Assessment Report (AHAR) to Congress. Office of Community Planning and Development. Washington, D.C.: U.S. Department of Housing and Urban Development. https://www.hudexchange.info/resources/documents/ahar-2013-part1.pdf

Iivonen, M., Sonnenwald, D.H., Parma, M., \& Poole-Kober, E. (1998). Analyzing and Understanding Cultural Differences: Experiences from Education in Library and Information Studies. Conference proceedings. Professional Group: Library Services to Multicultural Populations. 64th IFLA General Conference (August 16-August 21, 1998), Amsterdam. http://archive.ifla.org/IV/ ifla64/077-155e.htm

Iser, W. (1978). The Act of Reading: A Theory of Aesthetic Response. Baltimore, MD: John Hopkins.

Jaeger, P. T., Bertot, J. C., \& Franklin, R. E. (2010).
Diversity, inclusion, and underrepresented populations in LIS research. Library Quarterly 80, 175-181.

Jaeger, P., Bertot, J., \& Subramaniam, M. (2013). Preparing future librarians to effectively serve their communities. Library Quarterly, 83(3), 243-248.

Jaeger, P., Cooke, N., Feltis, C., Hamile, M., Jardine, J., \& Shilton, K. (2015). The virtuous circle revisited: Injecting diversity, inclusion, rights, justice, and equity into LIS from education to advocacy. The Library Quarterly: Information, Community, Policy 85(2): 150-171.

Kumasi, K. \& Hill, R. F. (2013). Examining the hidden ideologies within cultural competence discourses among library and information science students: Implications for school library pedagogy. School Libraries Worldwide, 19(1): 128-139.

Lance, K.C. (2005). Racial and ethnic diversity of U.S. library workers. American Libraries, 36(5), 41-43.

Layton, L., \& Brown, E. (2015, September 14). Number of homeless students in U.S. has doubled since before the recession. The Washington Post. http://wapo.st/1FIbaw2

Lytle, S. L. (2008). At Last: Practitioner Inquiry and the Practice of Teaching: Some Thoughts on "Better". Research in the Teaching of English 42(3), 373-379.

Mestre, L. S. (2010). Librarians working with diverse populations: What impact does cultural competency training have on their efforts? Journal Of Academic Librarianship, 36(6), 479-488.

Office of Diversity. (2012). Diversity counts. American Library Association. http://www.ala.org/offices/diversity/diversitycounts/divcounts.

Overall, P.M. (2009). Cultural competence: A conceptual framework for library and information science professionals. Library Quarterly, 79, 175-204

Shorter-Gooden, K. (2013). The culturally competent organization. Library Quarterly 83(3), 207-211.

Voyvodic, R. (2006). Lawyers meet the social context: Understanding cultural competence. Canadian Bar Review 84: 563-591.

Weaver, H.N. (2004). Explorations in Cultural Competence: Journey to the Four Directions. CA: Wadsworth Publishing.

White, A. (2012). Not Your Ordinary Librarian: Debunking the Popular Perceptions of Librarians (Chandos information professional series). Oxford, UK: Chandos. 